\title{
Rapid large-volume fluid administration through a multi-lumen central venous catheter: a simple modification
}

\author{
Hilary P. Grocott, MD, FRCPC, FASE - Ravi Raj, MD • \\ Hessam H. Kashani, MD, MSc
}

Received: 3 October 2019/Revised: 8 October 2019/Accepted: 9 October 2019/Published online: 21 October 2019

(C) Canadian Anesthesiologists' Society 2019

\section{To the Editor,}

The need for large volume and rapid fluid/blood administration is a common occurrence in the perioperative setting. Nevertheless, large-bore intravenous access for vigorous fluid administration is often not available. Indeed, even with central venous access, standard multi-lumen central venous catheters often have limited flow characteristics because of their relatively small-diameter lumens and longer lengths. Herein, we propose a method to modify a multi-lumen central catheter to allow for rapid large-volume fluid administration using materials commonly available in the operating room. ${ }^{1}$

One Hi-Flo ${ }^{\mathrm{TM}_{4}}$-Way Stopcock (Smiths Medical ASD Inc., Dublin, OH, USA) was connected to each of the Luer lock connections on a $16 \mathrm{~cm} 7 \mathrm{Fr}$. Two-Lumen Blue FlexTip $^{\circledR} \quad$ ARROWg $^{+}$ard Blue $^{\circledR}$ Catheter (Arrow International, Inc.; Reading, PA, USA) (Figure). The high-flow stopcocks were then connected to each other using a Double Male Luer Lock (Smiths Medical ASD, Inc.; Dublin, OH, USA) connector. The stopcocks were then connected at their proximal end to a single large-bore intravenous tubing attached to a large volume rapid transfusion system (FMS 2000 Fluid Management System, Belmont Instrument Corporation, Billerica, MA, USA). The stopcocks could be sequentially toggled to allow for flow through either lumen, or for simultaneous flow through both lumens of the catheter.

We tested this modified multi-lumen central venous catheter in simulated attempts to rapidly administer fluid with flow through either lumen, or for simultaneous flow through both lumens ( $n=5$, each configuration). After priming the FMS 2000 device with $500 \mathrm{~mL}$ of Ringer's lactate, the distal end of the central venous catheter was inserted into the device's hard-shell reservoir (to continuously recycle the priming fluid) and the automated $500 \mathrm{~mL} \cdot \mathrm{min}^{-1}$ setting was activated on the device's control panel. After a steady state of fluid administration was established (approximately 15-20 sec), the pressure in the system (automatically displayed by the FMS 2000) was recorded as was the maximum flow rate attainable. With flow directed through both lumens of the two-lumen central venous catheter, rapid fluid administration was achieved (up to $320 \mathrm{~mL} \cdot \mathrm{min}^{-1}$; Figure). This is considerably greater than that obtained through each lumen alone. 


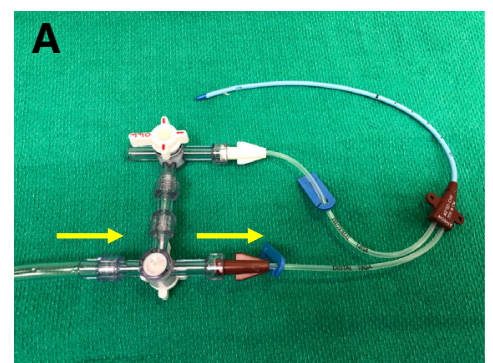

Distal Lumen

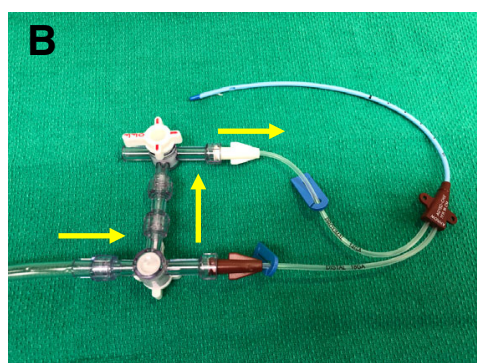

Proximal Lumen

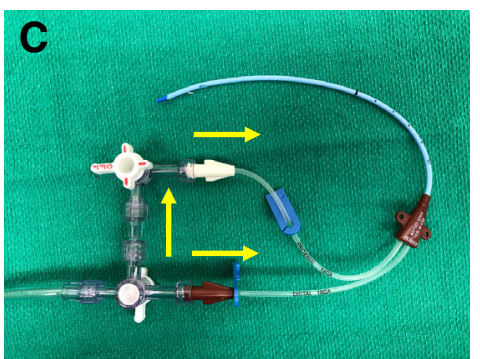

Combined Lumens

\begin{tabular}{|lccc|}
\hline Pressure $(\mathrm{mmHg})$ & $288(12)$ & $293(7)$ & $291(5)$ \\
\hline Flow Rate $\left(\mathrm{mL} \cdot \mathrm{min}^{-1}\right)$ & $77(3)$ & $247(4)$ & $320(7)$ \\
\hline
\end{tabular}

Figure Transfusion device line pressure and flow rate when rapidly administering intravenous fluid through a dual-lumen central venous catheter that has been modified to allow for simultaneous flow through both its lumens (see text). The flow through the single $18 \mathrm{G}$ distal lumen (A) when the bottom stopcock is turned off to the double male Luer lock connector is lower than that through the single

The use of this modification allows for rapid, largevolume fluid administration when a peripheral large-bore intravenous catheter is not available or where a multilumen central venous catheter is already in situ. It should be noted that the flow rates that we observed would be expected to be lower when packed red blood cells, platelets, ${ }^{2}$ or other colloids with higher viscosities are administered.

Conflicts of interest None declared.

Editorial responsibility This submission was handled by Dr. Steven Backman, Associate Editor, Canadian Journal of Anesthesia.

Financial disclosures None.
$14 \mathrm{G}$ proximal lumen (B) when the stopcock is turned off to the upper distal lumen. The highest flow rate occurs when the stopcocks are toggled so that flow happens simultaneously through both (C). The yellow arrows depict the direction of fluid flow. The data are represented as the mean (standard deviation), $n=5$.

\section{References}

1. Duggan LV, Marshall SD, Scott J, Brindley PG, Grocott HP. The MacGyver bias and attraction of homemade devices in healthcare. Can J Anesth 2019; 66: 757-61.

2. Hess AS, Ramamoorthy J, Connor J, Raife T, Hess JR. Stored platelet number and viscoelastic maximum amplitude are not altered by warming or rapid infusion. Transfusion 2019; 59: 29973001 .

Publisher's Note Springer Nature remains neutral with regard to jurisdictional claims in published maps and institutional affiliations. 